\title{
Use of text messaging to audit early clinical outcome following vasectomy in primary care
}

Graham Cooper, Jean Walker, Douglas Harris, Rorie Stewart, Douglas Nicol and Mike Ogg

\begin{abstract}
Fifty patients undergoing vasectomy at communitybased day surgery clinics in Grampian were invited to participate in follow-up by text message. Forty-six $(92 \%)$ of the patients responded, 14 reporting problems, generally of a minor nature, but severe enough to result in unscheduled time off work $(n=4)$ and oral antibiotic therapy $(n=5)$. Text messaging appears to be a useful form of communication for audit in this setting. The study findings have influenced the information provided by the authors at preoperative counselling.

Keywords

medical audit; primary care; text messaging; vasectomy.
\end{abstract}

\section{INTRODUCTION}

In 2009, 735 (79\%) of 928 vasectomies performed in the Grampian region were performed in primary care minor surgery clinics (E Thompson, PAS Database, NHS Grampian, personal communication, 2010), the majority by GPs with a special interest in minor surgery. The challenge of performing the clinical audit integral to surgical practice in this setting was the stimulus to this study.

Since first reported in 2003, ${ }^{1}$ the short message service (SMS), popularly termed 'text messaging', has been used for communicating with patients in several areas of medical work. In 2009, Roberts and Gorman ${ }^{2}$ reported using text messaging to collect information about overall satisfaction and postoperative pain from 25 patients who had undergone day surgery. The present study has examined the use of text messaging as a means of obtaining information about patients' clinical course following vasectomy.

G Cooper, MD, FRCS, consultant in community surgery, Grampian Community Surgery Programme, Minor Surgery Service, Aberdeen City CHP, Aberdeen. J Walker, BMedSci, BAO, DRCOG, MRCGP, DCHGP, Maryhill Practice, Elgin Health Centre, Maryhill, Elgin. D Harris, FRCGP, GP, Peterculter Medical Practice, Peterculter, Aberdeen. R Stewart, BMSc(Hons), MRCGP, GP, Oldmachar Medical Practice, Aberdeen. D Nicol, BMedBiol, FRCGP, MFHom, DRCOG, DFFP, clinical lead for minor surgery in general practice, Mintlaw Group Practice, Mintlaw, Aberdeenshire. M Ogg, RMN, RGN, CPN, CMS, DMS, general manager, Inverurie Hospital, Inverurie, Aberdeenshire.

Address for correspondence Graham G Cooper, Grampian Community Surgery Programme, Minor Surgery Service, Aberdeen City CHP, Bridge of Don Clinic, Cairnfold Road, Bridge of Don, Aberdeen, Scotland, AB22 8LD.

e-mail: graham.cooper5@nhs.net

Submitted: 7 October 2010; Editor's response: 29 October 2010; final acceptance: 19 November 2010.

(c)British Journal of General Practice 2011; 61: 280-282.

DOI: 10.3399/bjgp11X567135

\section{METHOD}

Between November 2009 and February 2010, 50 of 51 consecutive men (mean age 37 years, range 26-50 years) attending for vasectomy were recruited into the study. One patient declined to participate because he shared a mobile telephone with his wife.

Prior to the procedure, all patients were counselled by the first author and gave witnessed verbal consent to participate in an audit of their experience of vasectomy. They were asked to exchange mobile telephone numbers with the first author so that he could send them a text message approximately 4 weeks after the procedure, 'Mr Cooper calling. Have you had any problems?'. They were advised that an answer of 'Yes' or 'No' would be sufficient. A single reminder was sent to nonresponders.

The vasectomy procedures were performed in minor surgery clinics by the first four authors, under a spermatic cord block plus local skin infiltration using a standard traditional surgical technique. 


\section{RESULTS}

\section{Communications with patients}

Five patients made early contact with the first author (median 3 days after vasectomy, range 1-7 days), three by text message, two by telephone.

Fifty patients were sent text messages for audit purposes at a mean of 32 days after vasectomy (range 28-41 days). Forty-two responded to the first text. Four of the remaining eight patients replied to a second text message sent 11 days after the first text (range 5-24 days). Therefore, 46 $(92 \%)$ of the 50 patients responded, 44 by text messaging, two by telephoning the first author. Thirty-nine of the patients responded on the day of receiving the text, seven patients between 1 and 5 days later.

Two patients made additional contact with the first author at a later stage.

\section{Information received from patients}

Two of the five patients who made early contact were concerned about minor wound bleeding. Two wished for advice about unexpectedly severe pain and tenderness, and one had developed a haemoserous wound discharge on the seventh postoperative day. The first author resolved these issues with advice by text or telephone; the patients with minor wound bleeding were reassured, the remaining three were advised to make an appointment with their GP. One of the patients with pain required unscheduled sick leave.

Forty-six patients responded to the planned text for audit. Although they had been advised during counselling that a brief answer would be sufficient, many replied at length and therefore some subjective analysis of the information provided has

\section{Table 1. Problems following vasectomy} described by patients $(n=14)$.

\begin{tabular}{lc} 
Problem reported & Number \\
\hline Bleeding from wound & 3 \\
\hline Severe bruising & 1 \\
\hline Haematoma & 2 \\
\hline Severe pain & 3 \\
\hline Tenderness & 2 \\
\hline Clinically suspected scrotal infection & 5 \\
\hline Urinary tract infection & 1 \\
\hline Discharge from wound & 1 \\
\hline Wound dehiscence & 1 \\
\hline Inflammatory reaction to skin sutures & 1 \\
\hline Protrusion of deep suture & 1 \\
\hline Unilateral testicular swelling & 2 \\
\hline
\end{tabular}

\section{How this fits in}

Feedback after out-patient surgical procedures such as vasectomy may be difficult to obtain. Text messaging, used with appropriate care, can be a useful method of communication for surgical audit and can achieve a high percentage of patient compliance.

been required. Three additional text messages were sent by the first author to clarify issues raised, and three replies were received.

The 46 patients who responded included four of the five who had made early contact; two of these patients had made a good recovery and two had recovered from the initial problem but had developed further complications. Thirty-four of the remaining 42 patients, $74 \%$ of all responders, answered 'No' to the texted question, or gave an equivalent response indicating that they had had no problems, although 13 added supplementary comments to the effect that they had had symptoms such as discomfort, tenderness, or bruising, and six indicated that their skin sutures were still in situ. The remaining eight patients described problems varying from minor bleeding to clinically suspected scrotal infection (Table 1); five had been prescribed oral antibiotics by their GP, and one had been prescribed antibiotic cream for his wound. Three had required sick leave from work. Three patients had required attention for suture-related problems.

Of the two patients who contacted the first author after the planned exchange of text messages, one who had been well when texted on the 30th postoperative day had developed unilateral testicular swelling on the 41st day after vasectomy; the other patient requested general advice. Appropriate guidance was provided.

In summary, 14 patients reported problems at some stage after vasectomy: five who made early contact, eight at the time of audit by text, and one on the 41st postoperative day.

\section{DISCUSSION}

\section{Summary of main findings}

The compliance rate noted in the present study seems to indicate that text messaging is a generally acceptable form of communication for audit.

\section{Strengths and limitations of the study}

There are some potentially negative aspects of the method to consider. First, confidentiality must be carefully maintained. This issue was addressed by establishing that the patients in the study had exclusive access to their own mobile telephone 
and, as in the work described by Maher et $a l,{ }^{3}$ a generic message was used. Patients were able to confirm the source of the message by checking the telephone number given on the first author's business card before replying. Secondly, it needs to be emphasised to participants that the exchange of telephone numbers is not intended for postoperative care. There is a danger that telephoned or texted advice might discourage a patient from seeking more appropriate clinical review. Thirdly, text messaging may exclude some vulnerable groups of people who are unable to use the technology, or those living in remote rural areas. Finally, exchange of information by texting tends to be brief and, as in the present study, provides only the patients' subjective view of whether they had had 'any problems'.

\section{Comparison with existing literature}

Audit of outcome is essential to modern surgical practice and yet it poses many challenges. Information about problems following vasectomy may prove particularly difficult to obtain. Clinical review may be inconvenient for men of working age. In a report from South Africa, $36.7 \%$ of patients were lost to follow-up even after repeated invitations. ${ }^{4}$ Compliance with audit by questionnaire has been variable in published studies, for example, $42.3 \%{ }^{5}$ to $85 \% .^{6}$

\section{Implications for clinical practice}

Used carefully in an appropriate setting, text messaging can obtain information from a group of patients who may otherwise be difficult to followup. The findings of this study have influenced the counselling the authors offer prior to surgery, particularly with regard to the postoperative course patients may expect.

\section{Ethical approval}

Verbal consent was employed for this study and no signed consent form was used. Ethical approval for this clinical audit study was not requested.

\section{Competing interests}

The authors have stated that there are none.

\section{Discuss this article}

Contribute and read comments about this article on the Discussion Forum: http://www.rcgp.org.uk/bjgp-discuss

\section{REFERENCES}

1. Dyer O. Patients will be reminded of appointments by text message. BMJ 2003; 326(7402): 1281.

2. Roberts A, Gorman A. Short message service for outpatient data collection. Br J Anaesth 2009; 102(3): 436.

3. Maher JE, Pranian K, Drach L, et al. Using text messaging to contact difficult-to-reach study participants. Am J Public Health 2010; 100(6): 969-970.

4. Heyns CF, Trollip GS, Fisher M, et al. Vasectomy under local anaesthesia performed free of charge as a family planning service: complications and results. S Afr Med J 2009; 99(4): 238-242.

5. Choe JM, Kirkemo AK. Questionnaire-based outcomes study of nononcological post-vasectomy complications. J Urol 1996; 155(4): 1284-1286.

6. Skriver M, Skovsgaard F, Miskowiak J. Conventional or Li vasectomy: a questionnaire study. Br J Urol 1997; 79(4): 596-598. 